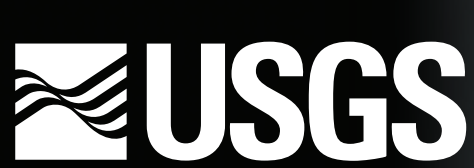

science for a changing world

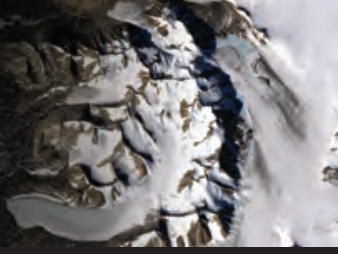

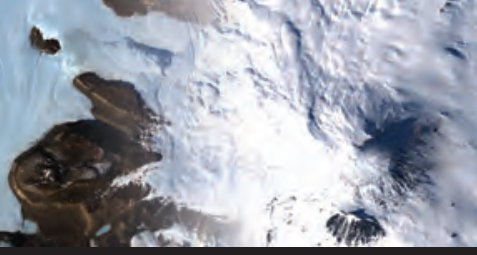

In cooperation with the National Science Foundation

\title{
Landsat Image Mosaic of Antarctica (LIMA)
}

\section{http://lima.usgs.gov}

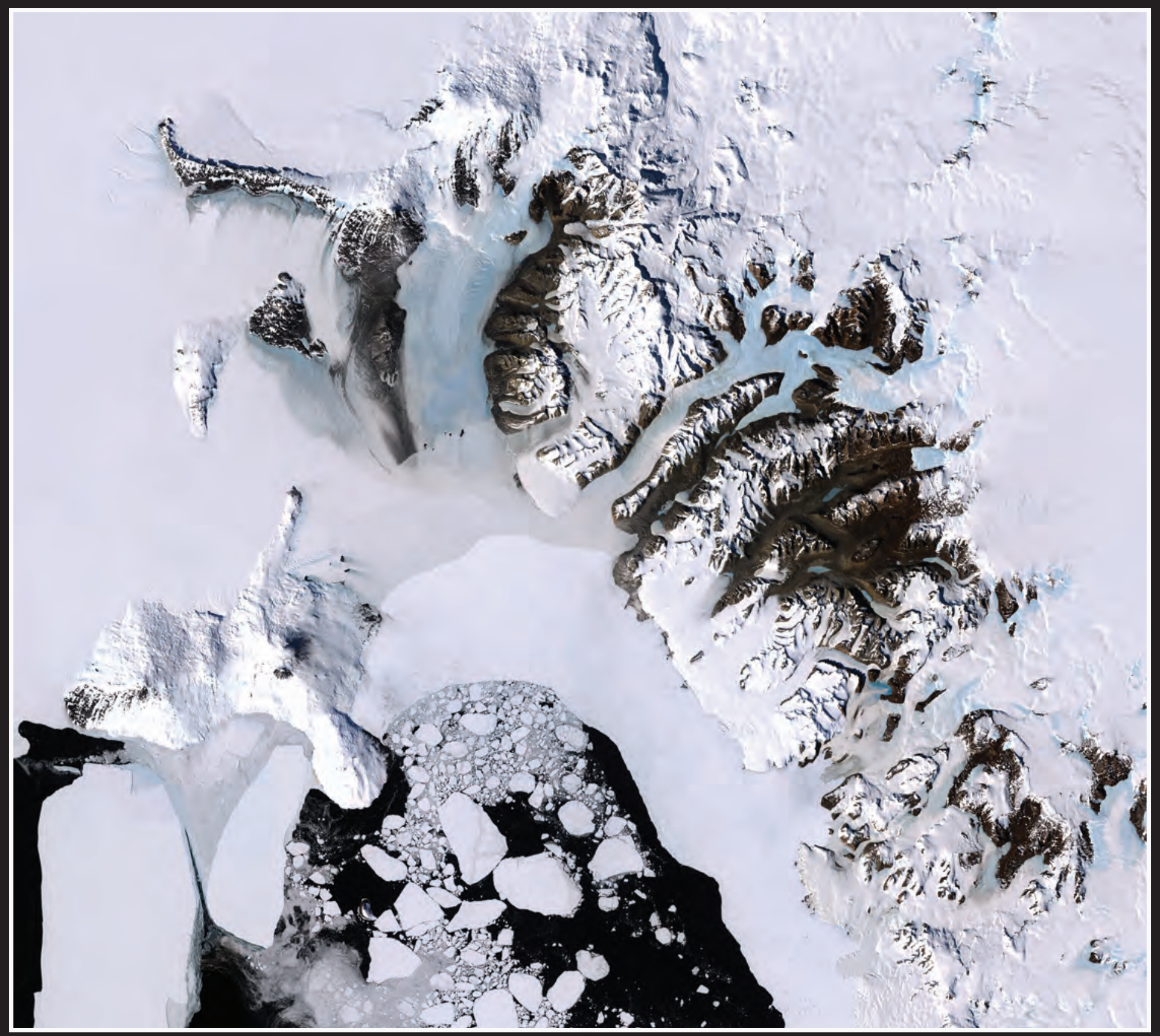

Antarctica-a frozen dream comes to life through the extraordinary focus of LIMA, where you can pan and zoom in to view areas of the continent never before seen with such clarity. Discover the different blue tones of ice in glaciers, lakes, and ice flows. Clearly discriminate between ice and snow. See jagged mountains and the dry (ice-free) valleys. Follow the coast and feel as though you are watching calving icebergs. This section of the Natural-Color, Pan-Sharpened LIMA (bands 3, 2, 1) includes McMurdo Station (United States), the largest research base in Antarctica, at the tip of Hut Point Peninsula on Ross Island. Also visible are the Erebus Glacier Tongue, the Koettlitz and Ferrar Glaciers, and the Royal Society Range. 

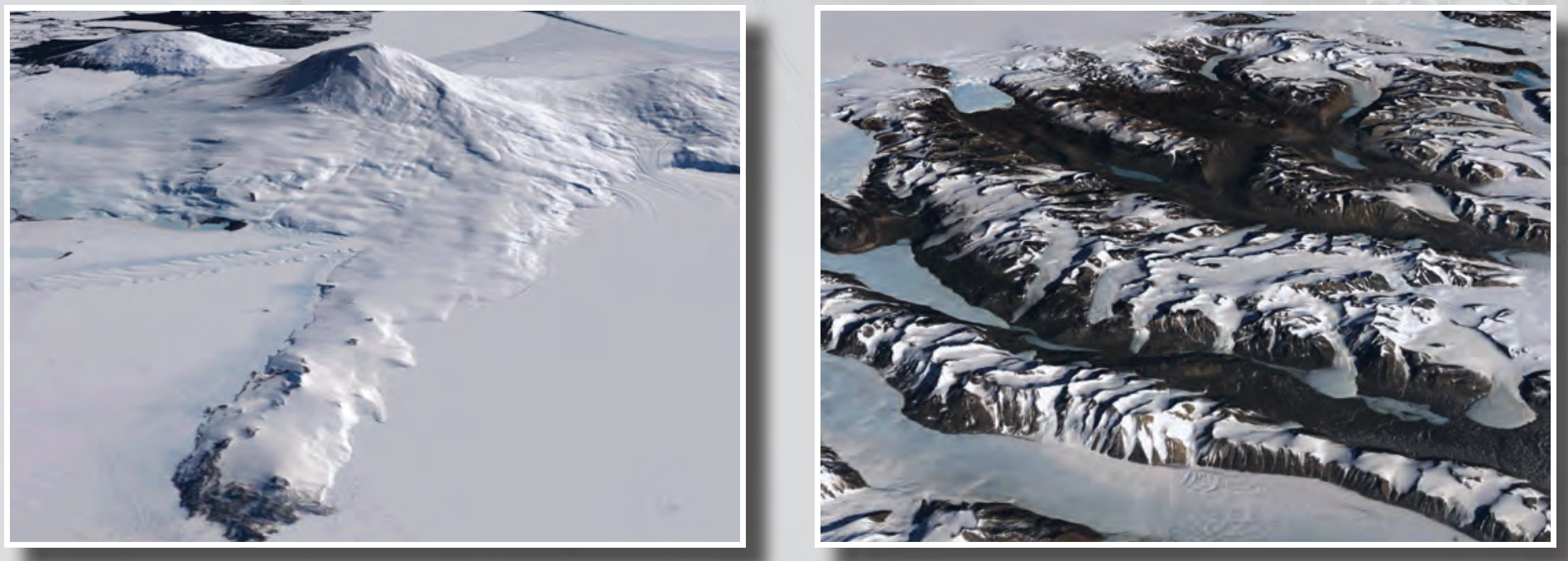

Imagery from the Natural-Color, Pan-Sharpened LIMA (bands 3, 2, 1). Left: Oblique view of Ross Island with McMurdo Station at the tip of Hut Point Peninsula in the foreground. Right: Oblique view of McMurdo Dry Valleys.
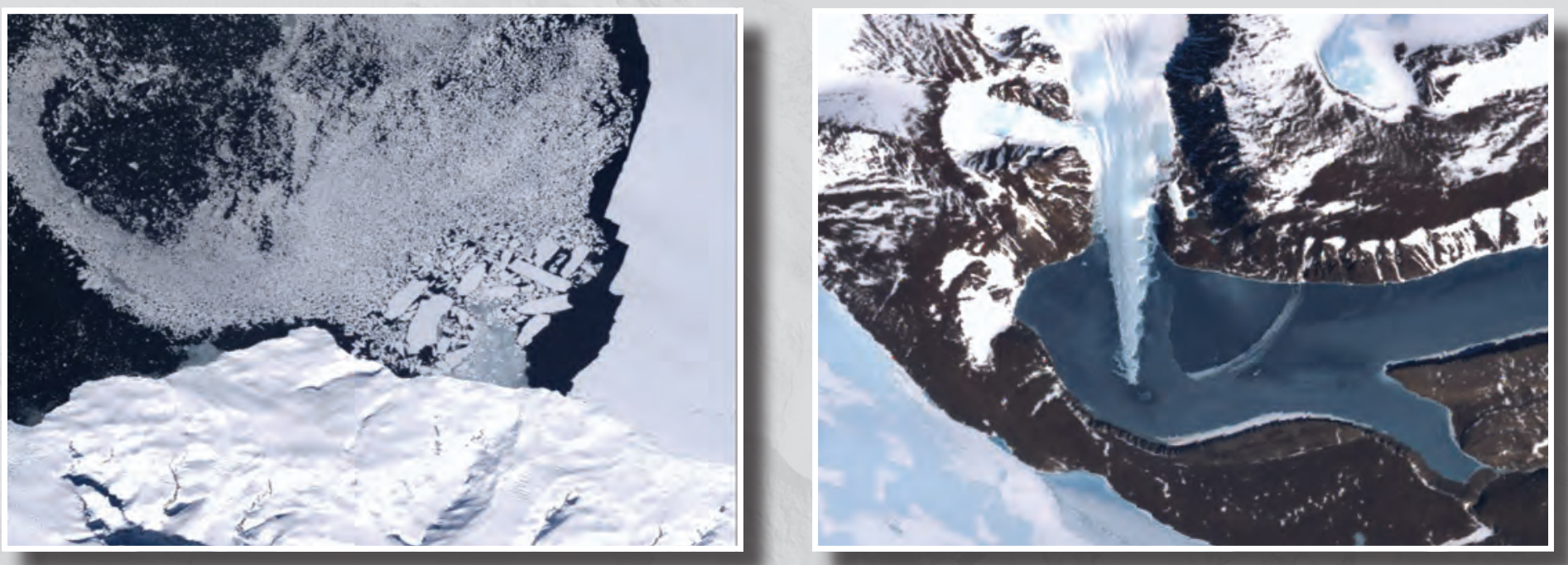

Left: Damocles Point on the east coast of Alexander Island at the base of the Antarctic Peninsula, with calved icebergs. Right: A slender glacier tongue feeds into Radok Lake, a 6-kilometer (4-mile) meltwater lake near the Amery Ice Shelf.

For most of us, Antarctica was at best a distant acquaintance. Now, with the Landsat Image Mosaic of Antarctica (LIMA), we are on intimate terms. In stunning, upclose and personal detail, LIMA brings Antarctica to life.

Explore this virtually cloudless, seamless, most geometrically accurate, and highest resolution satellite mosaic of Antarctica.

A team of scientists from the U.S. Geological Survey, the British Antarctic Survey, and the National Aeronautics and Space Administration, with funding from the National Science Foundation, created LIMA in support of the International Polar Year (IPY; 2007-08).

As the first major scientific outcome of the IPY, LIMA truly fulfills the IPY goals. LIMA is an international effort, supports current scientific polar research, encourages new projects, and helps the general public visualize Antarctica and changes happening in this southernmost environment. Researchers and the general public can download LIMA and all component Landsat scenes at no charge.

\section{Discover How LIMA Was Created}

\section{Scene Selection}

The team created LIMA from over 1,000 Antarctica scenes taken by the Enhanced Thematic Mapper Plus (ETM+) sensor since Landsat 7 launched in 1999. The selection process began with the team searching through 8,000 scenes with 0 to 10 percent cloud cover. As much as possible, scientists chose adjacent scenes from a single Landsat pass over Antarctica because of the consistent sun angles and weather conditions. For areas without a cloud-free scene, over 15,000 more scenes were assessed for minimum cloudiness and for cloud-free portions of the scenes. Finally, areas with overlapping scenes were studied to select the best quality data available. For areas without any clear images, scientists used the least cloudy image. 


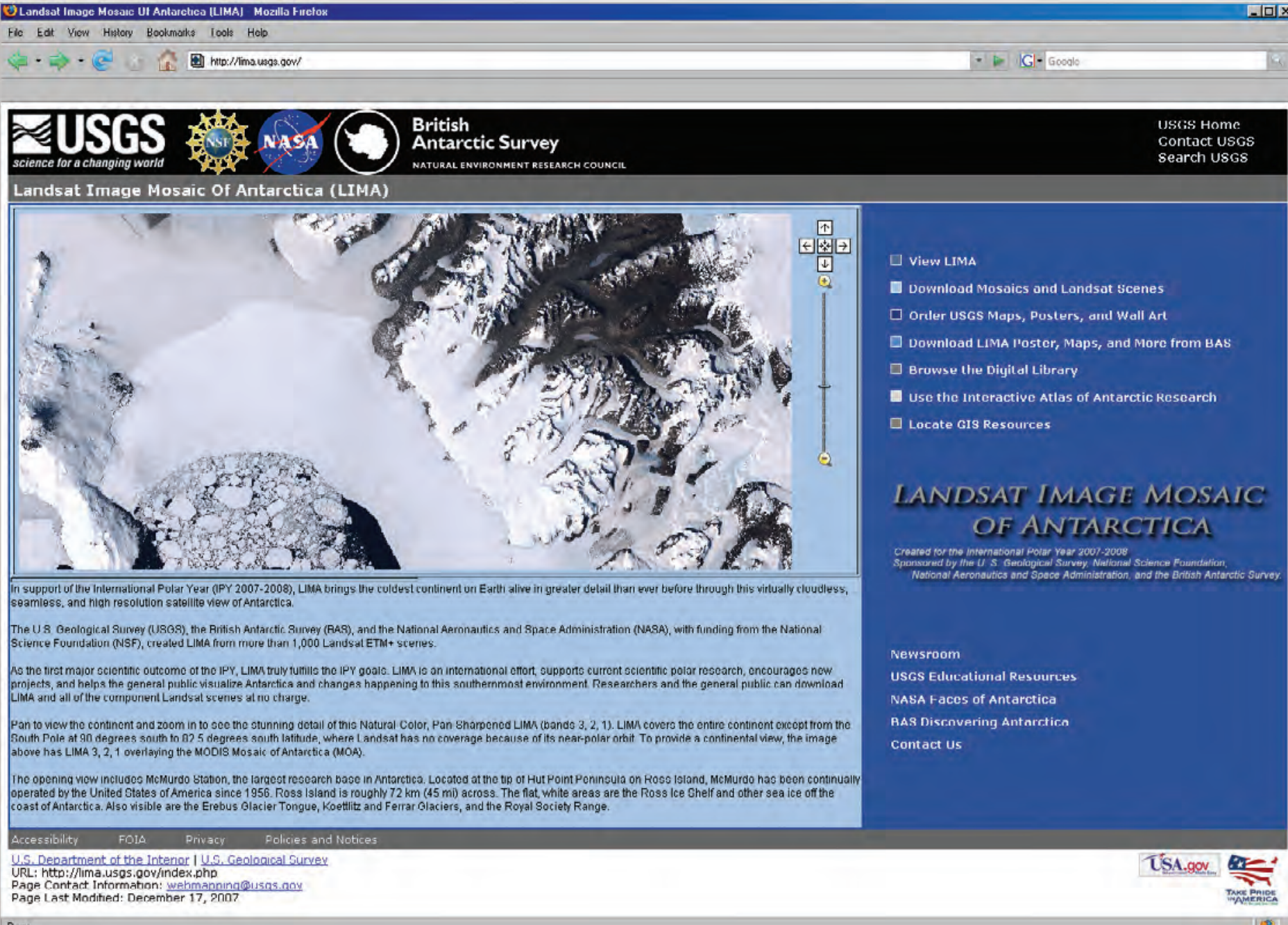

\section{Scene Preparation}

The LIMA team processed each Landsat scene with elevation data and sun-angle correction to ensure surface features were accurately represented. The sun's angle in Antarctica gives the appearance of a setting sun. As Landsat passes over Antarctica, the low sun angle makes outer edges of the continent appear brighter than areas closer to the South Pole, so scenes have bright and dark areas. The team corrected for these inconsistent sun angles and shadows. Without this process, mosaicking would produce a patchwork effect.

\section{Mosaic Process}

The team used custom software to merge the processed Landsat scenes. Because of the extensive number of scenes available, the team stacked scenes, so almost all areas with cloud cover were overlapped with cloudless data from an adjacent scene. To eliminate a few noticeable seam lines along scene edges, the team trimmed scene boundaries to follow natural features where possible. Individual scenes were then combined into 25 blocks of merged data. The team combined and stored these 25 blocks as 5 virtual mosaics. This process avoided problems associated with maintaining and working with extremely large files (about 1 terabyte for each mosaic if actually merged together into one file). The virtual mosaics were then processed and output in 2-gigabyte GeoTiff files.

\section{Explore LIMA and the LIMA Web Site}

Discover the natural wonders of Antarctica by exploring each version of LIMA. Pan and zoom in to uncover areas of Antarctica never before seen with such clarity.

The View LIMA page makes it simple to tour the beautiful and haunting landscape of Antarctica with easy-to-use pan and zoom tools. Visit the Atlas of Antarctic Research map viewer for a more extensive exploration of LIMA with geographic information system resources (such as location names). The Download Mosaics and Landsat Scenes page features all the versions of LIMA, the original and processed Landsat scenes, and previous mosaics of Antarctica for quick tiled downloads at no charge.

The map viewers display the mosaics and Landsat scenes in polar stereographic projection with Web Map Service. All GeoTiff tiled downloads include Federal Geographic Data Committee compliant metadata.

Find a wealth of other resources at http://lima.usgs.gov including USGS Antarctic maps and products, the spectacular LIMA poster from the British Antarctic Survey, as well as a digital library of Antarctic and IPY research and information. 


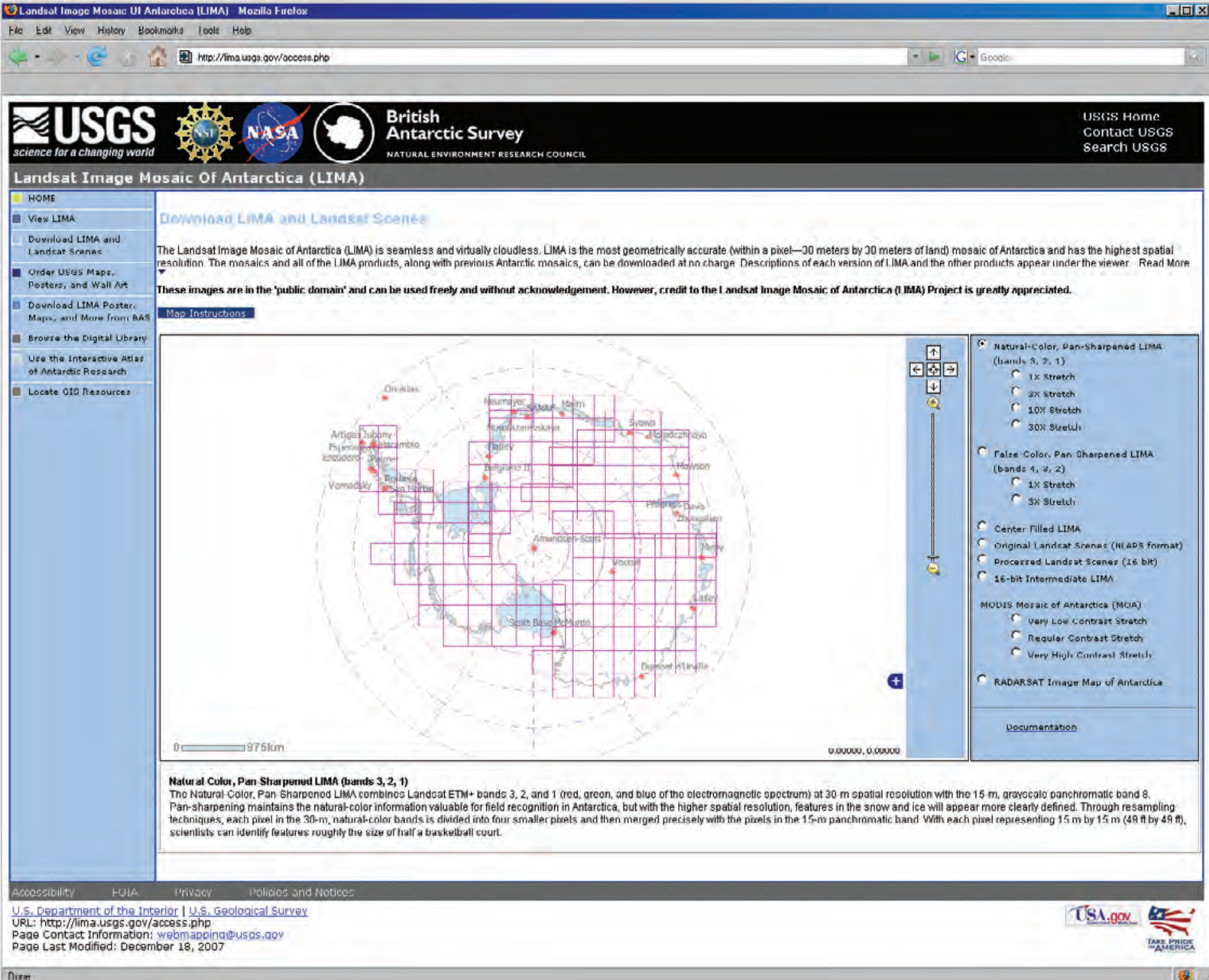

Natural-Color, Pan-Sharpened LIMA (bands 3, 2, 1) combines Landsat ETM+ bands 3, 2, and 1 (red, green, and blue of the electromagnetic spectrum) at 30-meter spatial resolution with the 15-meter, grayscale panchromatic band 8. Pan-sharpening maintains the natural-color information valuable for field recognition in Antarctica; but with the higher spatial resolution, features in the snow and ice will appear more clearly defined. Through resampling techniques, each pixel in the 30-meter, natural-color bands is divided into four smaller pixels and then merged precisely with the pixels in the 15-meter panchromatic band. With each pixel representing 15 meters by 15 meters ( 49 feet by 49 feet), scientists can identify features roughly the size of half a basketball court.

False-Color, Pan-Sharpened LIMA (bands 4, 3, 2) incorporates infrared data, allowing scientists to more clearly discriminate between ice and snow. This version merges Landsat ETM+ bands 4, 3, and 2 (near-infrared, red, and green of the electromagnetic spectrum) at 30-meter spatial resolution with the 15 -meter, grayscale panchromatic band 8 .

Enhanced Versions of LIMA use different stretches to bring out features in Antarctica that would not normally be visible. In the same way that sunglasses soften the glare, these enhancements tone down the brightness of the entire image while preserving the color balance.

Learn more about the other LIMA products at http://lima.usgs.gov including the Center-Filled LIMA, the Original Landsat Scenes (National Land Archiving Production System format), the Processed Landsat Scenes (16 bit), and the 16-bit Intermediate LIMA.

For more information about LIMA and http://lima.usgs.gov, please contact:

Customer Services

U.S. Geological Survey

Center for Earth Resources

Observation and Science (EROS)

47914 252nd Street

Sioux Falls, SD 57198-0001

Tel: $\quad 800-252-4547$

Tel: $\quad$ 605-594-6151

TDD: 605-594-6933

Fax: 605-594-6589

Email: custserv@usgs.gov 